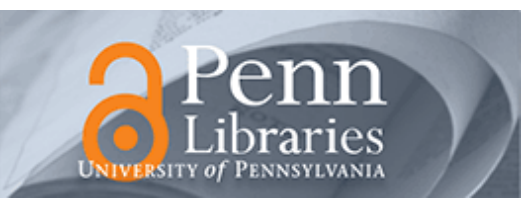

University of Pennsylvania

ScholarlyCommons

September 2002

\title{
An Extended Frequency Range CMOS Voltage-Controlled Oscillator
}

\author{
Chao Xu \\ PMC-Sierra, Inc. \\ Winslow Sargeant \\ National Science Foundation \\ Kenneth R. Laker \\ University of Pennsylvania, laker@seas.upenn.edu \\ Jan Van der Spiegel \\ University of Pennsylvania, jan@seas.upenn.edu
}

Follow this and additional works at: https://repository.upenn.edu/ese_papers

\section{Recommended Citation}

Chao Xu, Winslow Sargeant, Kenneth R. Laker, and Jan Van der Spiegel, "An Extended Frequency Range CMOS Voltage-Controlled Oscillator", . September 2002.

Copyright 2002 IEEE. Reprinted from Proceedings of the 9th IEEE International Conference on Electronics, Circuits and Systems (ICECS 2002), Volume 2, pages 425-428.

Publisher URL:http://ieeexplore.ieee.org/xpl/tocresult.jsp?isNumber=22423

This material is posted here with permission of the IEEE. Such permission of the IEEE does not in any way imply IEEE endorsement of any of the University of Pennsylvania's products or services. Internal or personal use of this material is permitted. However, permission to reprint/republish this material for advertising or promotional purposes or for creating new collective works for resale or redistribution must be obtained from the IEEE by writing to pubs-permissions@ieee.org. By choosing to view this document, you agree to all provisions of the copyright laws protecting it.

This paper is posted at ScholarlyCommons. https://repository.upenn.edu/ese_papers/62

For more information, please contact repository@pobox.upenn.edu. 


\title{
An Extended Frequency Range CMOS Voltage-Controlled Oscillator
}

\author{
Abstract \\ This paper presents an extended frequency range CMOS monolithic voltage-controlled oscillator (VCO) \\ design. A negative feedback control algorithm is used to automatically adjust the VCO range according to \\ the control voltage. Based on this analog feedback control algorithm, the VCO achieves a wide range \\ without any pre-register settings. Low phase noise is achieved by using both coarse control and fine \\ control in VCO. A $600 \mathrm{MHz}$ to $3.3 \mathrm{GHz}$ monolithic CMOS PLL based on this wide range and low phase \\ noise VCO has been fabricated in TSMC $0.18 \mu \mathrm{m}, 1.8 \mathrm{~V}$ CMOS technology and is used in many different \\ applications such as FC, GE, and SONET etc.

\section{Keywords} \\ VCO, PLL, voltage-controlled oscillator, phase-locked loop, phase-noise \\ Comments \\ Copyright 2002 IEEE. Reprinted from Proceedings of the 9th IEEE International Conference on Electronics, \\ Circuits and Systems (ICECS 2002), Volume 2, pages 425-428. \\ Publisher URL:http://ieeexplore.ieee.org/xpl/tocresult.jsp?isNumber=22423 \\ This material is posted here with permission of the IEEE. Such permission of the IEEE does not in any way \\ imply IEEE endorsement of any of the University of Pennsylvania's products or services. Internal or \\ personal use of this material is permitted. However, permission to reprint/republish this material for \\ advertising or promotional purposes or for creating new collective works for resale or redistribution must \\ be obtained from the IEEE by writing to pubs-permissions@ieee.org. By choosing to view this document, \\ you agree to all provisions of the copyright laws protecting it.
}




\title{
An Extended Frequency Range CMOS Voltage-Controlled Oscillator
}

\author{
Chao $\mathrm{Xu}^{[1]}$, Winslow Sargeant ${ }^{[2]}$, Kenneth Laker ${ }^{[3]}$, Jan Van der Spiegel ${ }^{[3]}$ \\ [1] PMC-Sierra, Inc. Allentown, PA, 18102 \\ [2] National Science Foundation, Arlinton, VA, 22230 \\ [3] Department of Electrical Engineering, University of Pennsylvania \\ chao_xu@pmc-sierra.com
}

[ABSTRACT] This paper presents an extended frequency range $\mathrm{CMOS}$ monolithic voltage-controlled oscillator (VCO) design. A negative feedback control algorithm is used to automatically adjust the VCO range according to the control voltage. Based on this analog feedback control algorithm, the VCO achieves a wide range without any pre-register settings. Low phase noise is achieved by using both coarse control and fine control in VCO. A $600 \mathrm{MHz}$ to $3.3 \mathrm{GHz}$ monolithic CMOS PLL based on this wide range and low phase noise $\mathrm{VCO}$ has been fabricated in TSMC $0.18 \mathrm{um}, 1.8 \mathrm{~V}$ CMOS technology and is used in many different applications such as FC, GE, and SONET etc.

\section{INTRODUCTION}

With the exponential growth of the number of Internet nodes, the volume of the data transported by its backbone continues to rise rapidly. Among the available transmission media, optical fibers have the highest bandwidth with the lowest cost, serving as an attractive solution for the Internet backbone. However, the electronic interface proves to be the bottleneck in designing high-speed optical system. This fact, combined with the ever-shrinking time to market, indicates that designs based on flexible modules and macro-cells have great advantages. In the optical communication in a backbone infrastructure, flexibility means, for example, programmable bit rates requiring a phase-locked loop (PLL) with robust operation over a wide frequency range. A wide range PLL could be used by different protocols and applications so that we maximize the reusability and reduce the time to market [1].

A wide range PLL requires a wider tuning range of voltage-controlled oscillator (VCO). In this paper, a fully integrated CMOS VCO with an extended frequency range from $600 \mathrm{MHz}$ to $3.3 \mathrm{GHz}$ is described. In section II, following a brief overview of conventional architecture for ring type based VCO design, the proposed architecture is described to solve the problems of conventional methods. A negative feedback control algorithm automatically adjusting VCO frequency range is used to extend the frequency range. A coarse control and fine control scheme is used to reduce the phase noise of VCO. In section III, circuits of this novel wide tuning range VCO are described. Measurement results are included in section IV. And finally concluding remarks are included in section $\mathrm{V}$.

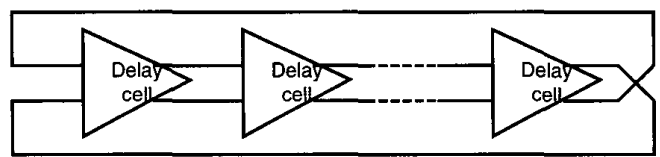

(a)

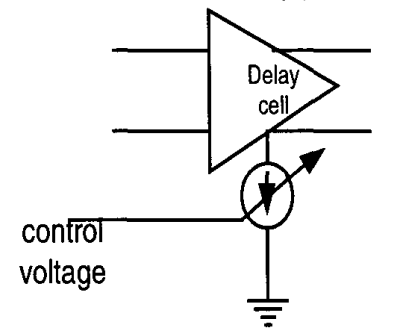

(b)

Figure 1 (a) Ring Typed Oscillator

(b) Voltage-controlled Delay Cell

\section{ARCHITECTURE}

\section{A. Limited Range Problem of Conventional VCOs}

The most common used architecture for the voltagecontrolled oscillator in CMOS technology is voltage controlled ring typed oscillator [2]. It consists of several delay cells forming a close loop as shown in Figure 1(a). The output clock frequency is determined by the delay of each delay cell which is in turn controlled by the control voltage. A wide frequency range of oscillator means a wide tuning range for each delay cell.

The delay cell is usually a differential pair with a tail current and some active loadings. The delay of the delay cell is controlled by the value of the tail current shown in Figure 1(b). There are some difficulties associated with this architecture to achieve the wide tuning range. By using a single tail current, the tuning range is limited by the control voltage range. The control voltage range is usually constraint by the power supply voltage, i.e. $0 \leq V_{\text {control }} \leq V_{d d}$. If we choose the small tail current, the tail current is still not large enough even that the control voltage reach the up limit so that the high end frequency range of VCO is small. On the other hand, if we choose the large tail current, the tail current is still 


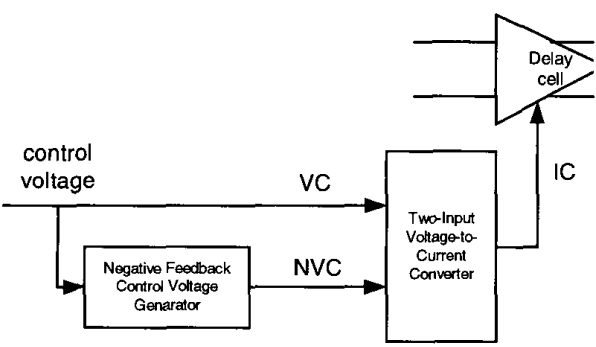

Figure 2. Block Diagram of the Proposed Architecture

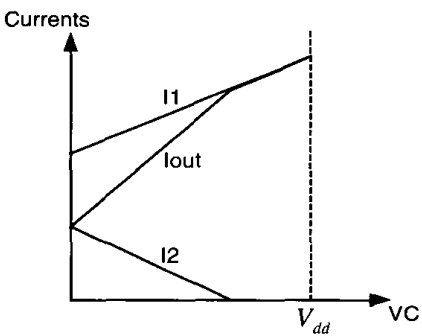

Figure 3 . The relation between the currents and the control voltage

large even that the control voltage reached the lower limit so that the lower end frequency range of $\mathrm{VCO}$ is large.

\section{B. Proposed Negative Feedback Control Architecture}

In order to solve the limited range of conventional VCO architecture, the negative feedback controlled architecture is proposed. Figure 2 shows a block diagram of the proposed architecture. This architecture includes three blocks: a negative feedback control voltage generator, a two-input voltage to current converter and delay cells. The negative feedback control voltage generator converts the control voltage supplied by the PLL into the feedback control voltage which will be inputted to the voltage-tocurrent converter block. The two-input voltage-to-current converter converts the two control voltage inputs $\mathrm{VC}$ and NVC to the current IC which is supplied to the delay cell block. And, finally, the delay cell block delays the input signal to the output signal whose delay is controlled by the control current IC.

\section{Negative Feedback Control Voltage Generator Design}

The negative feedback control voltage generator takes the control voltage VC (supplied by PLL) as an input and

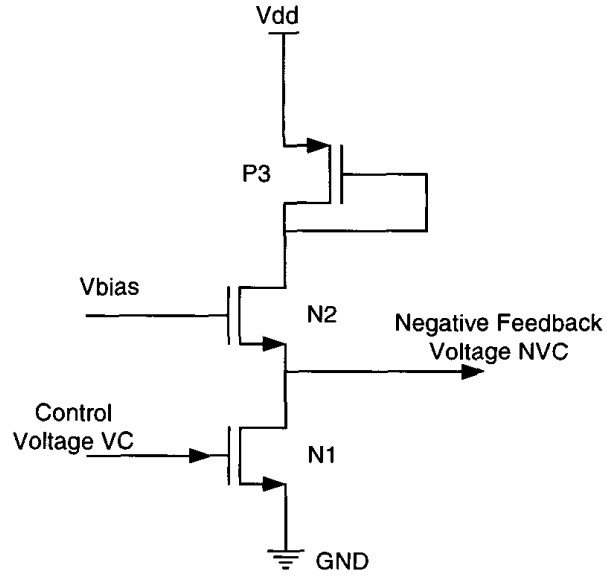

Figure 4. Negative Feedback Control Voltage Generator

generates the negative feedback control voltage NVC. This block doesn't need any additional pre-settings such as register bits or reference voltages for comparators. The purpose of this block is that when the input control voltage $\mathrm{VC}$ is low, the output negative feedback control voltage should be high. On the other hand, when the input control voltage VC is high, the output negative feedback control voltage should be low.

\section{Two-input Voltage-to-Current Converter Design}

The two-input voltage-to-current converter accepts the two control voltages VC and NVC as inputs and generates the control currents to each delay cell in the VCO. The purpose of this block is to generate the wide range currents with the limited range control voltage. The output current is designed as the subtraction of two current sources controlled by the two input voltages: control voltage supplied by PLL loop and the negative feedback control voltage. The relations between Iout, I1, $\mathrm{I} 2$ and the control voltage VC are shown in Figure 3. I1 increases with the control voltage VC (See curve I1 in Figure 3). I 2 is controlled by the negative feedback control voltage which decreases with the increase of VC. So I 2 decreases with the control voltage VC(See curve I2 in Figure 3). Iout=I1-I2 and is shown as the curve Iout in Figure 3. So when the control voltage VC is small, the effective output current Iout is small although the current source Il controlled by VC is large. But when the control voltage $\mathrm{VC}$ is high, the effective output current Iout is equal to I1 which is high because the current source 12 is 0 and doesn't reduce the effective output current Iout. So the current range is effectively expanded. 


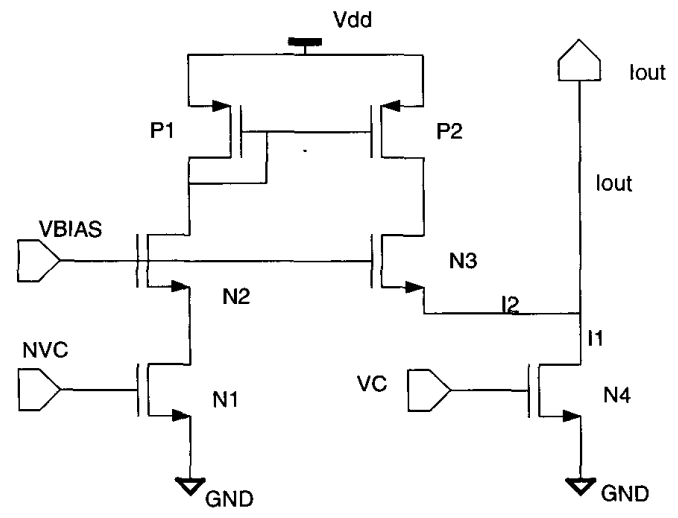

Figure 5. Two-input V2I Converter

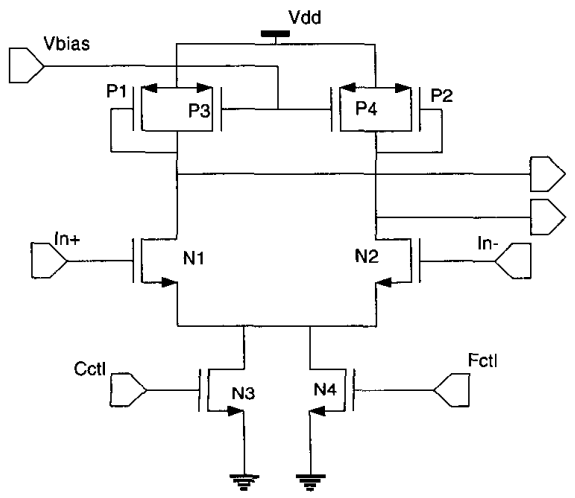

Figure 6. Delay Cell Circuit

\section{E. Coarse Control and Fine Control Design}

An addition to the basic architecture described above is noteworthy. The above arrangements for extended frequency range VCO results a large gain of VCO. Coarse control and fine control architecture is also used in PLL to reduce the gain of the $\mathrm{VCO}$ and reduce the jitter and phase noise [3]. The fine control of VCO will only take $10 \%$ of the total control voltage of the $\mathrm{VCO}$ and tremendously reduced the jitter and phase noise. The above negative feedback scheme combined with coarse control and fine control architecture generates a wide frequency range and low phase noise VCO.

\section{CIRCUIT DESIGN}

\section{A. Negative Feedback Control Voltage Generator Circuit}

The negative feedback control voltage generator is based on a common-source amplifier. The transistor diagram is shown in Figure 4. There are two NMOS transistors N1

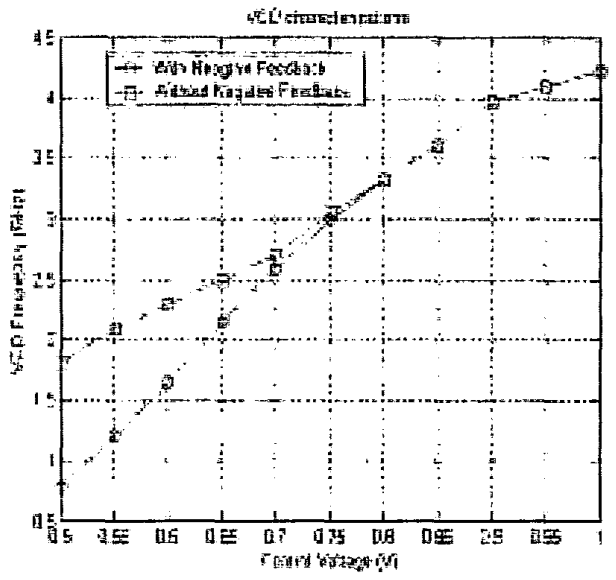

Figure 7. VCO Tuning Curve

and $\mathrm{N} 2$ and one PMOS transistor P1. The input signal is connected to the gate of $\mathrm{N} 1$ and the gate of $\mathrm{N} 2$ is connected to a bias voltage. $\mathrm{P} 1$ is diode-connected as a load and N1 is a single stage common source amplifier. The output signal is taken from the drain of N1. So when the input $\mathrm{VC}$ is low, NMOS transistor $\mathrm{N} 1$ is in cut-off region, the drain of the $\mathrm{N} 1$ will be pulled to a high voltage. On the other hand, when the input VC is high, N1 is on and pull the drain voltage almost to ground, i.e. the output voltage NVC will be very small.

\section{B. Two-input Voltage-to-Current Converter Circuit}

The two-input voltage-to-current converter circuit is shown in Figure 5. Control voltage VC controls the current source $\mathrm{N} 4$ and negative control voltage NVC controls the current source $\mathrm{N} 1$ which is mirrored by transistors N2, P1, P2. The output current Iout is equal to I2 subtracted from I1.

\section{Delay Cell Circuit}

The delay cell circuit is shown in Figure 6. The delay cell is differential pair with loading and bias controls. The self-biased techniques are used to reduce the jitter and process variations [4]. The coarse and fine control scheme is carried out by using two different tail current sources. The transistors N1, N2, N3, N4, P1, P2 are working in saturation modes while the $\mathrm{P}$ transistors $\mathrm{P} 3$ and $\mathrm{P} 4$ are biased in linear range as voltage controlled resistor loads.

\section{MEASUREMENT RESULTS}

The VCO has been fabricated using 0.18 um seven-metal CMOS process. The VCO is running in PLL and self-test circuit is built into the chip in order to measure the VCO performance. The negative feedback feature can be turned 


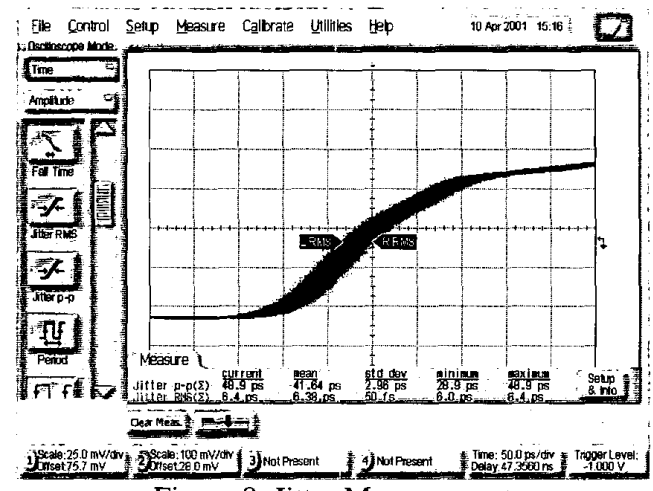

Figure 8. Jitter Measurement

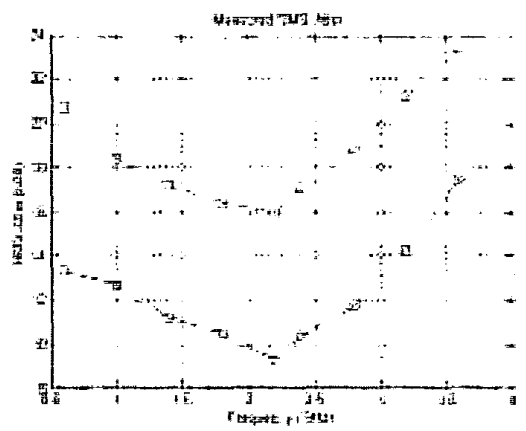

Figure 9. Measured PLL Output Jitter

on or off. The measured tuning range of VCO is shown in Figure 7. From the tuning curve, we can see the proposed architecture tremendously expanded the VCO frequency range in the lower end down to $600 \mathrm{MHz}$. So it can be used for Gigabit Ethernet and Gigabit Fiber Channel

\begin{tabular}{|l|l|}
\hline Process & $\begin{array}{l}\text { 0.18um 7-metal CMOS } \\
\text { process }\end{array}$ \\
\hline Power Supply & $1.8 \mathrm{~V}$ \\
\hline Active Area & $160 \mathrm{~mm} 270 \mathrm{um}$ \\
\hline $\begin{array}{l}\text { Current } \\
\text { Consumption }\end{array}$ & $20 \mathrm{~mA} @ 3.125 \mathrm{GHz}$ \\
\hline $\begin{array}{l}\text { Operating } \\
\text { Range }\end{array}$ & $\begin{array}{l}600 \mathrm{MHz}-3.3 \mathrm{GHz} \text { with } \\
\text { margins }\end{array}$ \\
\hline
\end{tabular}

Table I. Performance Summary of the Fabricated $\mathrm{VCO}$

which run in $1 \mathrm{GHz}$ to $2 \mathrm{GHz}$ frequency range. The RMS jitter of the output clock of the PLL based on the VCO is also measured. WaveCrest is used to measure the jitter. The Figure 8 shows the jitter measurement at $2.5 \mathrm{GHz}$ output clock. In the chip, we have two PLL loops. The
VCO in one loop doesn't have coarse and fine control scheme and the VCO in the other loop has enabled the coarse and fine control scheme. The jitters of both PLL clocks are measured and shown in Figure 9. From Figure 9, we can see the coarse and fine control scheme improve the jitter performance of the VCO. The following Table I show the performance summary of the fabricated VCO. The VCO has the frequency range from $600 \mathrm{MHz}$ to $3.3 \mathrm{GHz}$ with enough margins for different process corners. The VCO draws about $20 \mathrm{~mA}$ current when it is running at $3.125 \mathrm{GHz}$.

\section{CONCLUSIONS}

This paper presents an extended frequency range CMOS monolithic voltage-controlled oscillator (VCO) design. A negative feedback control algorithm is used to automatically adjust the VCO range according to the control voltage. Based on this analog feedback control algorithm, the VCO achieves a wide range without any pre-register settings. Low phase noise is achieved by using both coarse control and fine control in VCO. A $600 \mathrm{MHz}$ to $3.3 \mathrm{GHz}$ monolithic CMOS PLL based on this wide range and low phase noise VCO has been fabricated in TSMC 0.18um, 1.8V CMOS technology and is used in many different applications such as FC, GE, and SONET etc.

\section{REFERENCES}

[1] P. Larsson, "A 2-1600-MHz CMOS Clock Recovery PLL with Low-Vdd Capability", IEEE Journal Solid-State Circuits, vol. 34, no. 12, pp. 1951-1960, December 1999

[2] B. Razavi, Edited, "Monolithic Phase-Locked Loops and Clock Recovery Circuits Theory and Design", New York: IEEE Press, 1996

[3] C. Xu, W. Sargeant, K.R. Laker, J. Van der Spiegel, "Fully Integrated CMOS Phase Locked Loop with $30 \mathrm{MHz}$ to $2 \mathrm{GHz}$ locking range and $\pm 35 \mathrm{ps}$ jitter", Proc. of the 8th IEEE International Conference on Electronics, Circuits and Systems, September, 2001, Malta

[4] J.G. Maneatis, "Low-Jitter Process-Independent DLL and PLL Based on Self-Biased Techniques", IEEE. Journal Solid-State Circuits, vol 31, no. 11, pp. 17231732, November 1996 